\title{
A CONTRIBUIÇÃO DO DESIGN THINKING NA EDUCAÇÃO
}

\section{RESUMO}

O presente artigo busca, a partir da literatura, apresentar o design thinking como uma abordagem voltada à criação da inovação e como esta abordagem vem sendo trabalhada na área da Educação. Apresenta o conceito de design thinking, suas características e ferramentas de acordo com o ponto de vista dos principais autores e realizadores da área. Características como empatia, colaboração, experimentação, que formam o tripé do design thinking, são apresentadas, assim como vários projetos ao redor do mundo voltados para a educação, que utilizam essa abordagem como princípio norteador de suas atividades, enfatizando a característica interdisciplinar da mesma e mostrando que por meio do design thinking a comunidade como um todo aprende, na ação colaborativa, a entender suas próprias necessidades e a resolvê-las.
1. Especialista, e-mail: aline.c.oliveira@edu. sc.senai.br

Palavras-Chave: Design thinking. Educação. Interdisciplinaridade. 


\section{INTRODUÇÃO}

O presente artigo busca, a partir da literatura, apresentar o design thinking como uma abordagem voltada à criação da inovação e como essa abordagem vem sendo trabalhada na área da Educação.

Segundo Brown e Wyatt (2010), as empresas estão adotando o design thinking porque as ajuda a serem mais inovadoras, diferenciando suas marcas e trazendo os seus produtos e serviços ao mercado mais rapidamente.

Assim, este trabalho está estruturado da seguinte maneira: a primeira seção apresenta as considerações metodológicas utilizadas para sua estruturação. $\mathrm{Na}$ segunda seção, aborda-se o conceito de design thinking, assim como suas ferramentas e principais técnicas de acordo com o referencial teórico pesquisado. $\mathrm{Na}$ terceira seção, é apresentado o conceito de iDesign, que é o design thinking aplicado à Educação. E, por fim, são apresentados alguns cases e projetos desenvolvidos no mundo que já utilizam esta abordagem para o desenvolvimento da educação. Para o desenvolvimento do artigo, utilizouse como base estudos relacionados ao design thinking e à aplicação desta abordagem na Educação, objetivando apresentar a característica interdisciplinar da abordagem, a partir do ponto de vista de Brown (2010), Educadigital (2013), Lockwood (2009) e Martin (2010a).

Dessa forma, o presente trabalho é construído basicamente por meio de pesquisa bibliográfica que, segundo Gil (2002,p. 44), "é desenvolvida a partir de material já elaborado, constituído principalmente de livros e artigos científicos", e, levando em consideração para a seleção da bibliografia pesquisada, no intuito de responder a pergunta de pesquisa que este estudo busca explorar que é: "como a abordagem do design thinking vem sendo aplicada na Educação atualmente?".

\section{DESIGN THINKING}

Aponta-se a seguir o conceito de design thinking, suas características e ferramentas de acordo com o ponto de vista de autores como Brown (2010), Lockwood (2009) e Martin (2010a).

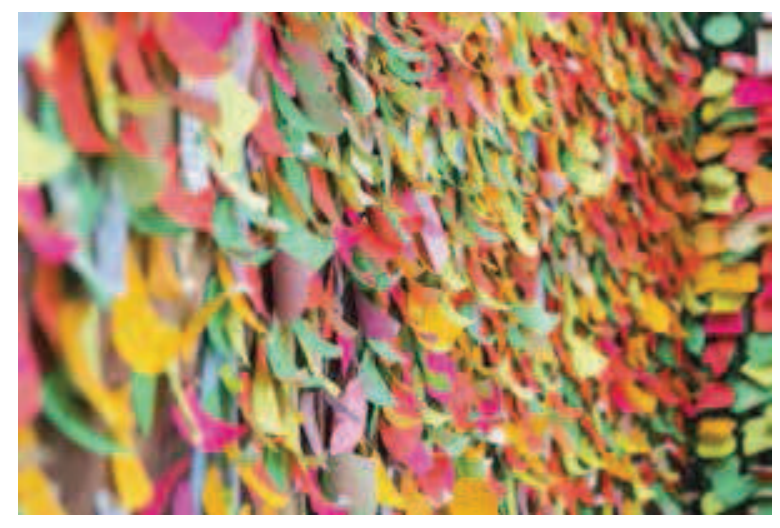

De acordo com Brown (2010), o design thinking (ou pensamento de design, que será tratado aqui como no original em inglês) tem seu início pelas habilidades aprendidas pelos designers ao longo do tempo, na busca pela correspondência entre as necessidades humanas com os recursos técnicos disponíveis, considerando as restrições práticas dos negócios.
Design thinking integra o que é desejável do ponto de vista humano ao que é tecno- lógica e economicamente viável, sendo possível aplicar técnicas de design a uma ampla gama de problemas, como represen- tado na figura 1. 
Figura 1: Critérios sobrepostos para implementação de boas ideias

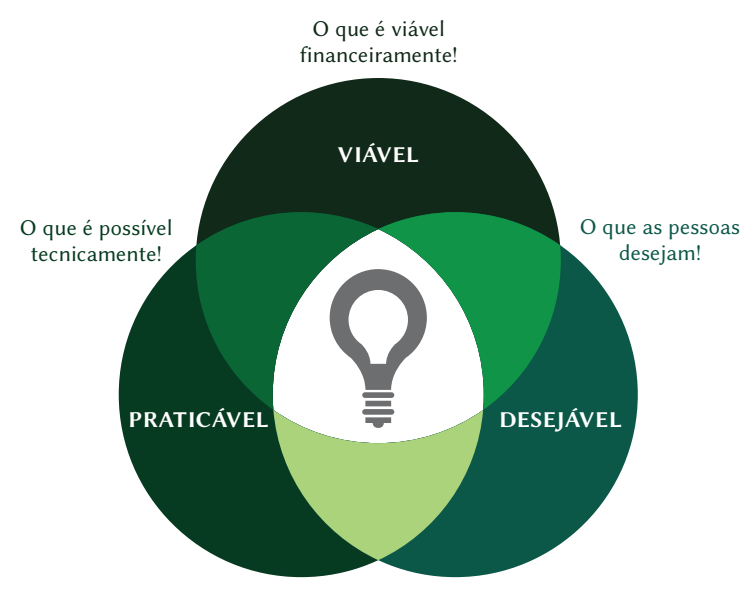

Fonte: Adaptado de Brown (2010b)

Para Simon (1969 apud SERRAT, 2010), é a mudança das condições existentes para as ideais. Para Brown (2010), a migração de designers para solucionar problemas sociais e comportamentais vem ocorrendo nos últimos anos, pois se tem compreendido que "a evolução do design ao design thinking é a história da evolução da criação de produtos à análise da relação entre pessoas e produtos e, por fim, entre pessoas e pessoas.” (p. 39).

Segundo Martin (2010a), o design thinking promove o equilíbrio entre o pensamento analítico e intuitivo, o que permite às organizações gerar inovações para aumentar eficiência e competitividade. Em essência,o design thinking permite que as corporações passem do complexo ao simples, por meio do que ele se refere como o "funil do conhecimento", representado pela figura 2, que reflete como o pensamento criativo do designer se forma.
Figura 2: O funil do conhecimento

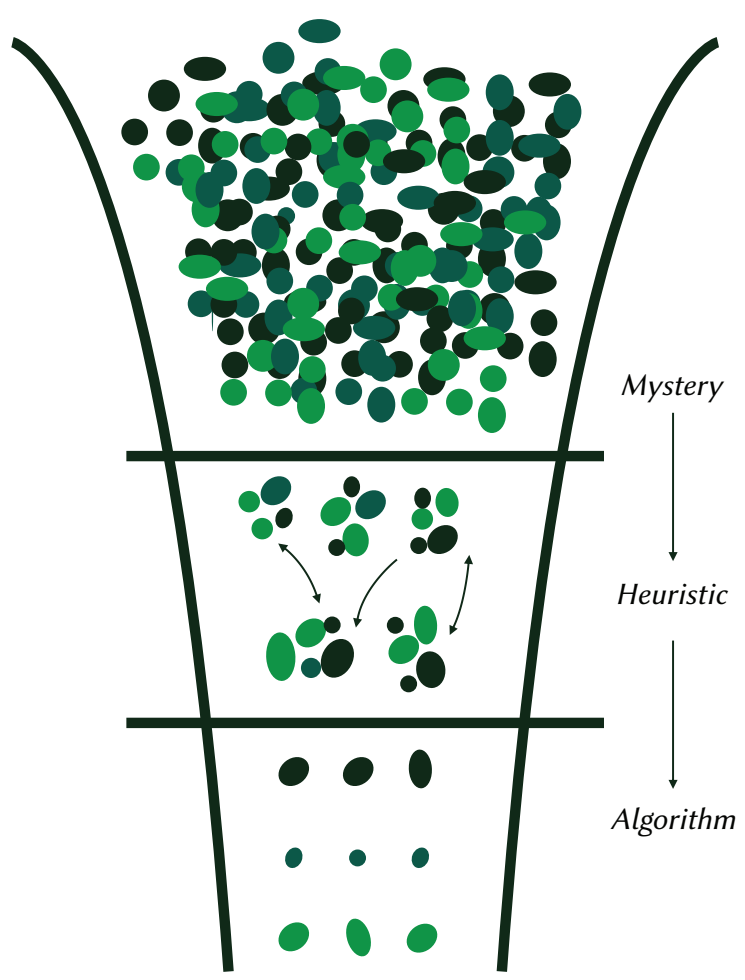

Fonte: Martin (2010b)

Martin (2010a) acredita que o design thinking é possível por meio da utilização da lógica abdutiva, conceito desenvolvido por James Peirce (1975). Tal forma de pensar permite que os design thinkers explorem possibilidades olhando para o futuro através das hipóteses formuladas antes da confirmação ou negação do caso.

Peirce (1975) explica a abdução como o processo para formar hipóteses explicativas.A dedução se baseia em algo que deve ser, o caminho indutivo mostra que algo é operatório, porém, a abdução faz uma mera sugestão de algo que pode ser. Para que os fenômenos possam ser aprendidos ou compreendidos, para Peirce (1975) somente a abdução pode funcionar como método. Ele defende que o raciocínio abdutivo são as hipóteses formuladas antes da confirmação ou negação do caso. 
O PROCESSO DE DESIGN THINKING

É MELHOR PENSADO COMO UM

SISTEMA DE ESPAÇOS QUE SE SO-

BREPÕEM, AO INVÉS DE UMA SE-

QUÊNCIA DE PASSOS ORDENADOS.

ESSES PASSOS SÃO: INSPIRAÇÃO,

IDEAÇÃO E IMPLEMENTAÇÃO.

Inspiração é o problema ou a oportunidade que motiva a busca de soluções; ideação é compreendido como o processo de gerar, desenvolver e testar ideias; implementação como o caminho que conduz a ideia a partir da fase de projeto até chegarà vida das pessoas. (BROWN; WYATT, 2010; SERRAT, 2010).

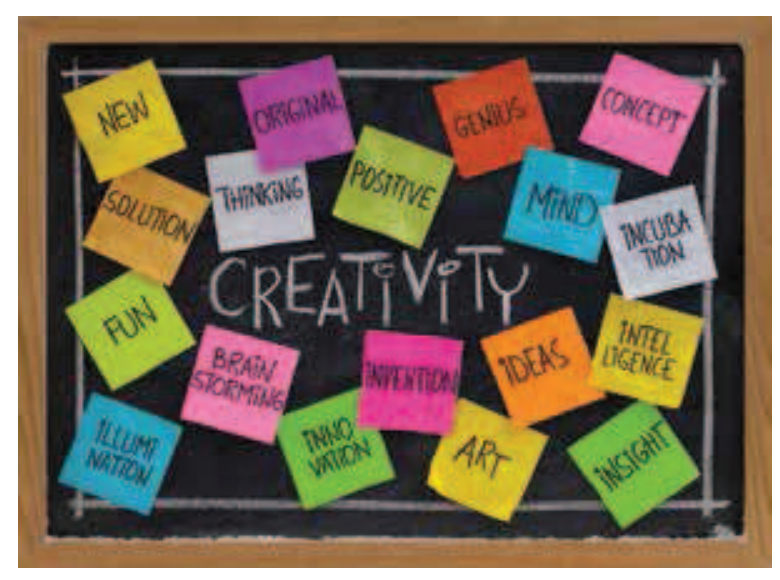

Design thinking não fornece as respostas corretas, ele muda o foco das perguntas. Embora muitas vezes as pessoas não podem dizer quais são suas necessidades, seus comportamentos reais podem fornecer pistas valiosas sobre sua gama de necessidades não satisfeitas. Henry Ford compreendeu isso quando observou que se perguntasse aos seus clientes o que eles queriam, eles responderiam um cavalo mais rápido. (BROWN; WYATT, 2010).

\section{1 "Tripé" do design thinking}

A base para o design thinking é a empatia, colaboração e experimentação das ideias. Para uma compreensão ideal sobre as características, os próximos tópicos trazem a explicitação de como as ferramentas utilizadas aplicam essas características no projeto.

\subsubsection{Empatia}

A técnica de observação é uma das ferramentas utilizadas para a "quebra" do problema entre as partes, e para que a equipe de design thinkers o compreenda melhor.Brown (2010) destaca que essa técnica serve para ver o que as pessoas não fazem, escutando o que elas não estão dizendo.

Os pontos mais interessantes e diferenciados da utilização dessa técnica para a compreensão dos problemas a serem resolvidos é que os dados qualitativos sobrepõem-se aos quantitativos, pois a pesquisa de campo é feita em grupos não focais e o maior interesse está em compreender os sentimentos, as emoções despertadas e a identificação daquela ideia com o entrevistado. Esses grupos, denominados por Brown (2010) por usuários "radicais", são assim chamados por viverem de forma diferenciada, pensam de forma diferenciada e consomem de forma diferenciada.Porém, a observação somente terá sucesso se o componente da equipe desenvolver esta, que é uma das características mais importantes do design thinker (BROWN, 2010), que é a empatia.

Empatia é a tentativa de ver o mundo através dos outros, compreender o mundo por meio das experiências alheias e de sentir o mundo por suas emoções. Para Brown (2010), o desenvolvimento da empatia é que talvez distinga o pensamento acadêmico e o design thinking. 
Design thinking significa ser mais empático, colaborativo (ALT, 2011), pois possuir essas características significa entender e envolver as pessoas em todas as fases da construção de um produto, visto que as pessoas que usarão o produto, sendo um coparticipante na sua criação, não apenas ficarão satisfeitas com o resultado, mas também serão incentivadoras da adoção da nova forma de fazer.

\subsubsection{Colaboração}

Colaboração é um dos tripés do design thinkinge se caracteriza pelo desenvolvimento de produtos “com” os clientes e não "para” os clientes.

\begin{abstract}
As pessoas, em vez de permitirem ser rotuladas como 'consumidores', 'clientes' ou usuários, agora podem se ver como participantes ativos no processo de criação; as organizações, de forma similar, devem passar a se sentir à vontade com o desgaste da fronteira entre o patenteado e o público, entre as organizações e as pessoas cuja felicidade, conforto e bem-estar lhes permitem ter sucesso. (BROWN, 2010, p. 56).
\end{abstract}

Brown (2012) acredita também que hoje as oportunidades estão neste espaço intermediário entre os consumidores passivos e os que projetarão para si tudo de que precisam. E que esse espaço intermediário é um nível mais elevado de colaboração, que servirá para obscurecer as fronteiras no nível de empresas e indivíduos.

\subsubsection{Experimentação}

Uma característica do design thinking é prototipar a ideia para que ela tome forma, a fim de que sejam conhecidos seus pontos fortes e fracos e que novos direcionamentos sejam identificados e lapidados. Os protótipos iniciais decidem se uma ideia tem ou não valor funcional. É o que ele chama de “rápido e sujo."(BROWN,2010).

De acordo com Vianna et al. (2012, p. 122), “o protótipo é a tangibilização de uma ideia, a passagem do abstrato para o físico de forma a representar a realidade - mesmo que simplificada - e propiciar validações".

Vianna et al. (2012) complementam dizendo que o protótipo é um instrumento de aprendizado sob a ótica da equipe do projeto, ao dar forma à ideia, aumentando os níveis de fidelidade da solução ao longo do processo e sob o ponto de vista do usuário, que interage com o modelo criado em diferentes níveis de contextualidade, tendo condições de avaliar e fornecer insumos para a evolução e o aperfeiçoamento do produto que está sendo criado. $\mathrm{O}$ protótipo pode ser uma representação conceitual da ideia até a construção de algo o mais próximo possível da solução, passando de baixa para alta fidelidade nesta transição.

A atividade de prototipagem no design thinking é recorrente de uma outra característica muito importante para definir esta abordagem, que é a experimentação. A experimentação permite que as novas soluções sejam colocadas mais rapidamente no mercado e que o mercado seja mais assertivo com suas inovações, pois uma inovação cega, aquele projeto que só é testado em sua fase final ou quando já está disponível no mercado, é considerada por Alt (2011) uma "roleta russa", ou seja, algo muito pouco inteligente a ser feito e que pode significar muito dinheiro jogado fora. A abordagem do design thinking obriga as equipes a estarem constantemente tentando visualizar e testar novas ideias, ainda em fase inicial, e isso se faz com a prototipagem, por meio da experimentação. 


\subsection{Design centrado no humano}

Para Lockwood (2009), design thinking é:

essencialmente um processo de inovação centrado no ser humano que enfatiza observação, colaboração, rápido aprendizado, visualização de ideias, construção rápida de protótipos de conceitos e análise de negócios dos concorrentes, para influenciar a inovação e a estratégia de negócio. (LOCKWOOD, 2009, p. 11).

Brown (2010) complementa a visão de Lockwood (2009) quando diz que o design thinking não é apenas uma proposta centrada no ser humano, sendo profundamente humana pela própria natureza, pois se baseia na capacidade do ser humano em ser intuitivo, reconhecer padrões, desenvolver ideias que tenham um significado emocional, ultrapassando as barreiras do funcional. Porém, tendo o cuidado de manter o equilíbrio entre sentimento, intuição e inspiração e a fundamentação no racional e analítico, "pois a abordagem integrada que reside no centro do processo de design sugere um terceiro caminho". (BROWN, 2010, p. 4).

\subsection{Equipes interdisciplinares}

No design thinking, as equipes possuem profissionais com capacidade de "conversar" entre as áreas, ou seja, compreender a área do outro profissional, ter a capacidade de discutir minúcias técnicas das áreas envolvidas no desenvolvimento do projeto. Em uma equipe de design thinkers, existem, por exemplo, psicólogos, engenheiros, antropólogos. Porém podem ser psicólogos que estudaram arquitetura, artistas com diploma de MBA, engenheiros com experiência em marketing. Brown (2010) denomina esses profissionais como "Profissional T", em que o eixo vertical da letra diz respeito a todo conhecimento técnico adquirido pela formação naquela área e a linha que cruza o "T" diz respeito à capacidade e à disposição de colaborar entre diferentes disciplinas.

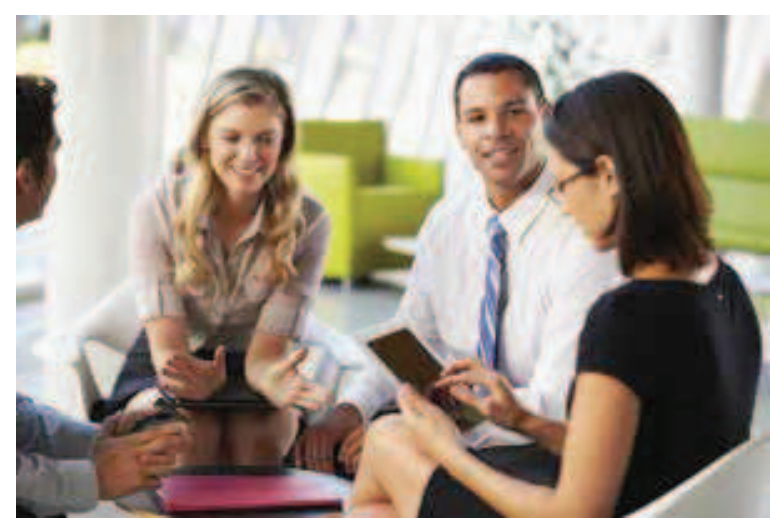

Para o autor, essa capacidade é o que distingue a mera equipe multidisciplinar de uma verdadeira equipe interdisciplinar, pois, na primeira, cada pessoa defende a própria especialidade técnica e o projeto acaba por se transformar em uma prolongada negociação entre os membros da equipe. Já na segunda equipe, todos os seus integrantes se sentem donos das ideias e assumem a responsabilidade por elas. (BROWN, 2010).

\subsection{Pensamento divergente $\mathrm{X}$ pensamento convergente}

No processo de design, a atividade foi dividida em etapas nas quais o designer utiliza pensamentos diferentes, segundo Jones (1978).

Divergência: é a ampliação dos limites e a obtenção de um espaço de investigação amplo e rico, que visa ampliar o conhecimento sobre o problema. Do pensamento divergente surge a capacidade de análise, desenvolve-se a habilidade da observação, sendo na maioria das vezes realizada individualmente, pois tem em seu enfoque o descobrimento das ideias. 
Transformação: elaboração mais amena, de alto nível criativo, insights, tudo o que contribui para converter o design em agradável tarefa. Divide-se em divergente (métodos de investigação de ideias - criatividade) e pura (auxilia na elaboração dos conceitos e utiliza métodos de exploração do problema).
Convergência: percepção de uma única alternativa mediante redução de incertezas até uma solução final. Indicado o uso de métodos de avaliação. No pensamento convergente, desenvolve-se a capacidade de síntese a partir das informações levantadas na análise, do descobrimento das ideias surge a criação da inovação, os insights e, normalmente, a convergência se dá em equipe.

Figura 3: Pensamento divergente e convergente
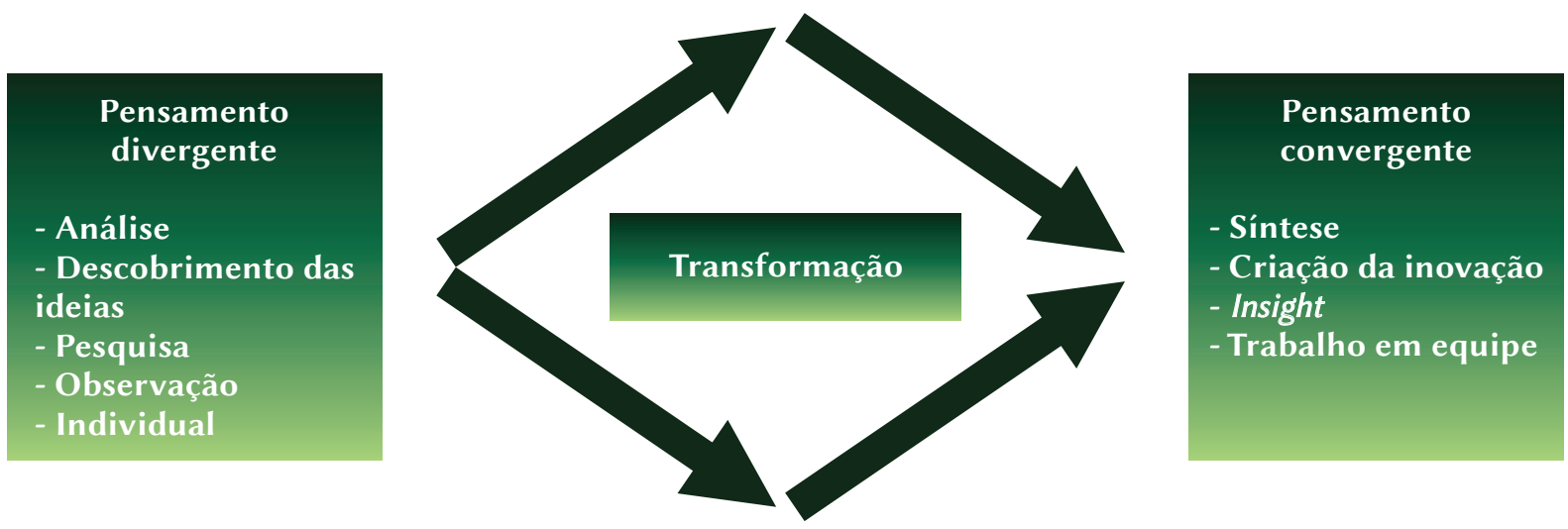

Fonte: Adaptado de Brown (2010)

$\mathrm{Na}$ divergência está o pensamento racional e o uso de conhecimentos explícitos para obter informações do contexto. Para Brown (2010), seu objetivo é multiplicar opções para criar escolhas. Aqui ocorre a análise de objetos que não podem ser vistos longe dos contextos sociais, culturais e históricos, e a extensão das preocupações além da viabilidade de produção e comercialização.

\subsection{Brainstorming e pensamento visual}

Brainstorming é uma técnica que estimula a geração de um grande número de ideias em um curto espaço de tempo (VIANNA et al.,2012). Conceito bastante difundido nas faculdades de
Administração, o brainstorming é considerado por Brown (2010) como a principal técnica que o design thinker possui para o desenvolvimento de produtos criativos. Segundo o autor, exercitar essa técnica é tão importante para a criatividade quanto exercitar o corpo é importante para um coração saudável.

Ainda segundo Vianna et al. (2012), existem alguns preceitos e algumas recomendações para que as equipes realizem brainstormings de sucesso, como prezar pela qualidade em detrimento da quantidade de ideias, pois a qualidade e assertividade dasideias geradas se atinge através da quantidade; evitar julgar as ideias, aceitar as ideias ousadas, combinar, adaptar, aprimorar, transformar e desmembrar as ideias são atitudes bem-vindas em um brainstorming. 


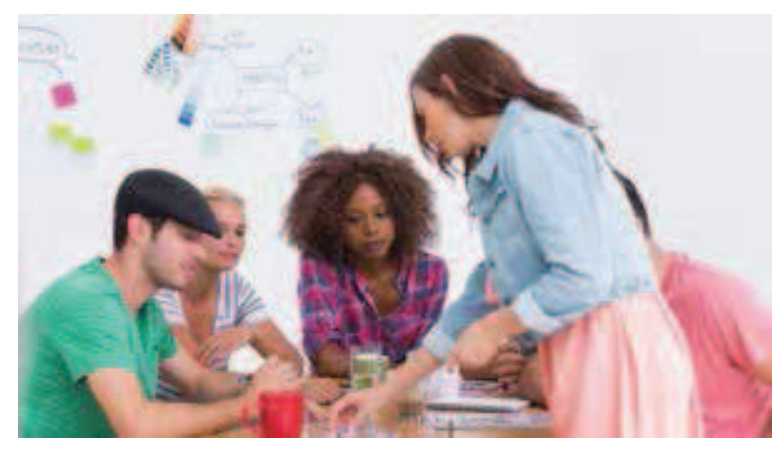

Tanto a realização do brainstorming quanto a expressão das ideias geradas, advinda do design, a prática do desenho para o desenvolvimento de produtos tangíveis ou intangíveis, tambémé uma característica marcante do design thinking. Brown (2010) compara a capacidade de expressar as ideias através de desenhos com um artista que expressa ideias alheias, captando tudo que vem do ambiente para o desenvolvimento de sua arte. A utilização de Post-it, produto da $3 \mathrm{M}^{\circledR}$, é outra característica marcante do pensamento do design thinker. Diversas ferramentas, como por exemplo o Business Model Canvas, modelo criado por Osterwalder (2013), que possui nove componentes básicos que mostram a lógica de como uma organização pretende gerar valor, sugere que sejam utilizados adesivos Post-it para o desenvolvimento de produtos de inovação, pois as ideias podem ser transicionadas de um lugar a outro dentro do quadro.

Nos próximos tópicos será explicado como a aplicação das técnicas e características apresentadas estão sendo aplicadas na área da Educação, corroborando para a caracterização interdisciplinar que o design thinking possui.

\section{DESIGN THINKING NA EDUCAÇÃO}

Para "aprender a aprender" há que estimular a curiosidade e o interesse por participar na construção do conhecimento. A simples transmissão de informação não capacita para a formação intelectual. Primeiro, é necessário "aprender a sentir" e logo "aprender a pensar". (TORO, 2002).
Os desafios colocados pelo mundo contemporâneo em educação podem ser resumidos como a exigência de transformar as práticas de ensino para preparar os alunos de todas as idades para a sociedade do conhecimento. (BEREITER; SCARDAMALIA, 2010; CHAI et al., 2011; MaCDONALD;HURSH,2006;PAAVOLA; HAKKARAINEN, 2005). 
Figura 4: $\mathrm{O}$ que o design thinking oferece para a Educação

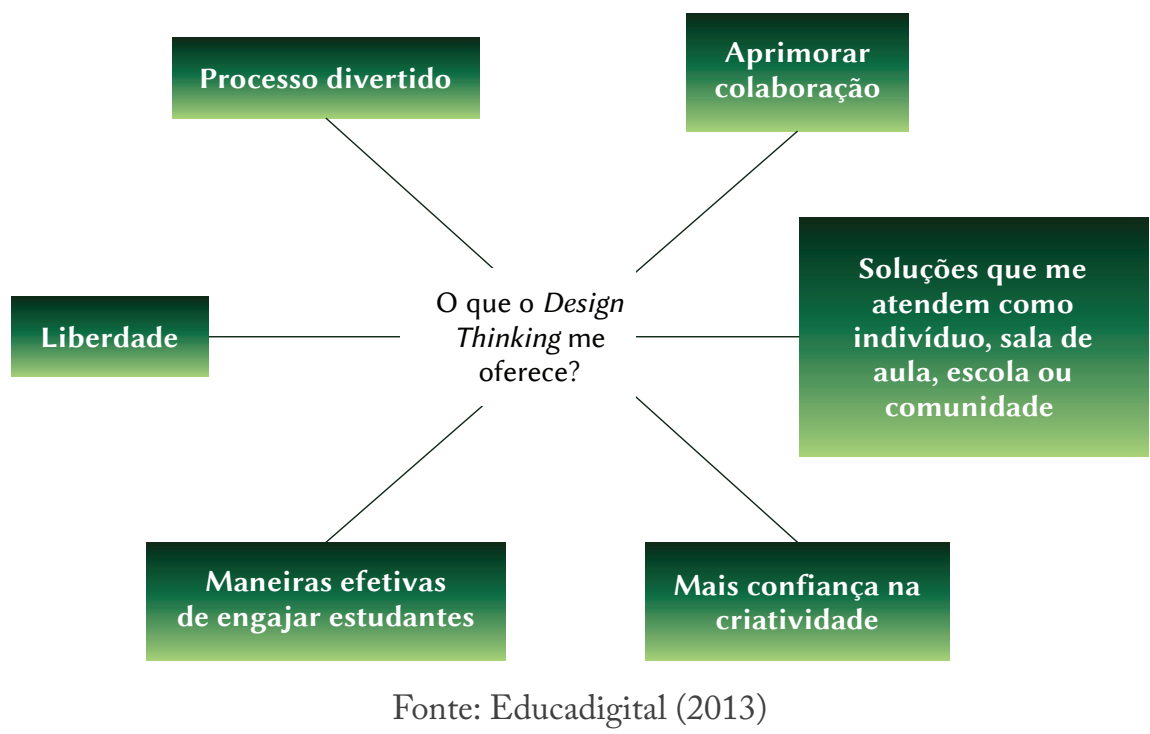

Os focos do sistema de educação na sociedade do conhecimento são direcionados a cultivar alunos que são hábeis a produzir conhecimento e produtos associados através de pesquisas transdisciplinares. A competência chave de trabalhadores na sociedade do conhecimento é a habilidade de criar conhecimento utilizável, e não somente conhecimentos que são governados por interesses acadêmicos. (BEREITER, 2002; VALIMAA; HOFFMAN, 2008).

Para encontrar desafios pautados por tal sociedade e colher os affordances ${ }^{1}$ pedagógicos de TIC's cada vez mais poderosas, é imperativo reconceitualizar educação; em particular, examinar coletivamente (envolvendo todos os níveis de educadores) as fundações epistemológicas e os propósitos da educação. Criação do conhecimento e design thinking são processos complexos que desprezam simples reduções. (TSAI, 2013).
As sete habilidades de sobrevivência para o século 21 envolvem: critical thinking e problem solving; colaboração e liderança por influência; agilidade e adaptabilidade; iniciativa e empreendedorismo; comunicação oral e escrita efetiva; acesso e análise de informação; curiosidade e imaginação. (SCHEER; NOWESKI; MEINEL, 2009).

Para as crianças, a escola é o único local em que as competências e habilidades podem ser aprendidas. Os sistemas educacionais estão sendo pressionados para prover os valores sociais e a atitude, além das experiências construtivistas. Ao contrário dessa demanda, os sistemas americanos (dos EUA), assim como alemães, têm um foco forte nas habilidades cognitivas. (NOWESKI, 2012).

Design thinking une com sucesso modelos da Psicologia, Economia e Pedagogia. A comunicação da equipe e as habilidades sociais em

\footnotetext{
${ }^{1}$ Para James J. Gibson, affordances são "possibilidades latentes no ambiente, mensuráveis objetivamente e independentes da capacidade de reconhecê-los mas dependentes das capacidades físicas dos indivíduos”. (GIBSON, 1977, p. 44, tradução nossa).
} 
relação a mal-entendidos, opiniões divergentes, emotividade interior e rivalidade entre si e outras preferências, bem como encontrar ativamente uma solução são desafiados em todas as fases, em que a interação é exigida o tempo todo,em todas as direções. (NOWESKI,2012).
Na prática, de acordo com Educadigital (2013), a aplicação do design thinking na abordagem do ensinar e do aprender se dá com as seguintes fases: descoberta, interpretação, evolução, experimentação e ideação.

Figura 5: Processo de design

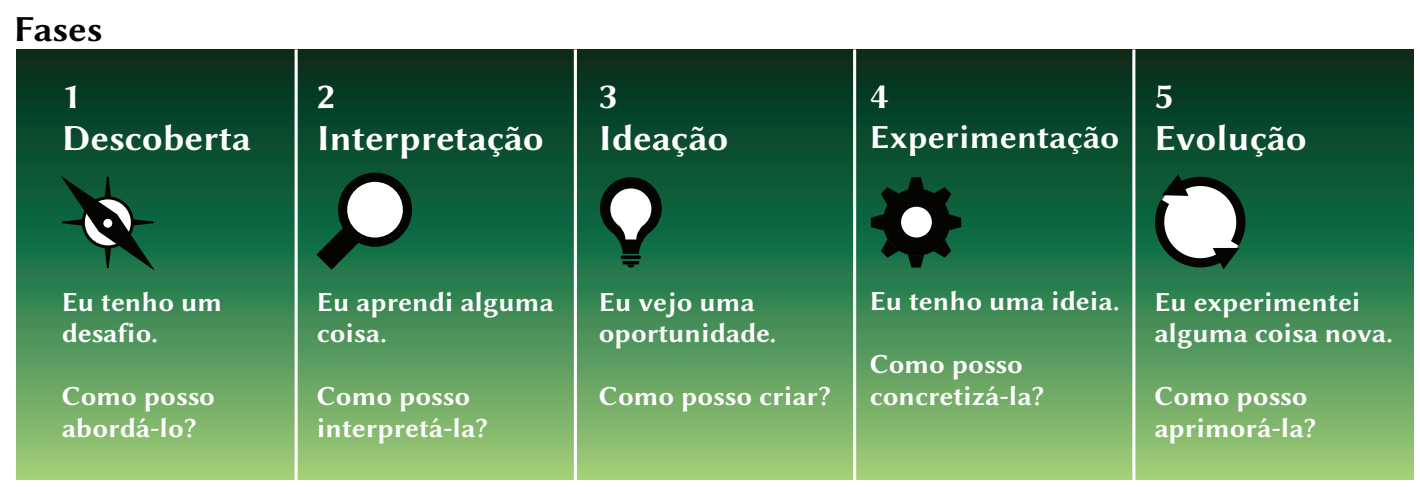

\begin{tabular}{|c|c|c|c|c|}
\hline \multicolumn{5}{|l|}{ Passos } \\
\hline \multirow{2}{*}{\multicolumn{5}{|c|}{$\begin{array}{l}1 \text { - } 1 \text { Entenda o } \\
\text { desafio }\end{array}$}} \\
\hline & & & & \\
\hline $\begin{array}{l}1 \text { - } 3 \text { Reúna } \\
\text { inspirações }\end{array}$ & $\begin{array}{l}2 \text { - } 2 \text { Procure por } \\
\text { significados }\end{array}$ & & & \\
\hline
\end{tabular}

Fonte: Adaptado de Educadigital (2013)

A fase da descoberta é a fase da compreensão do desafio, da preparação da pesquisa e reunião das inspirações. Nessa fase, a equipe é montada, as fontes de inspiração são identificadas, o roteiro da pesquisa é montado, o aprendizado com os especialistas e com o usuário é reunido.

$\mathrm{Na}$ fase da interpretação, histórias são contadas, documentadas e compartilhadas, insights são definidos, descobertas decifradas, o significado para a pesquisa é encontrado e a oportunidade é estruturada através de lembretes visuais, transformando insights em ações.

$\mathrm{Na}$ fase de ideação, os ideais são gerados, o brainstorming é preparado, ideias promissoras são selecionadas, ideais são refinados e a ideia é descrita.

A experimentação propõe a criação de protótipos e obtenção de feedbacks.

A fase da evolução se caracteriza por acompanhar o aprendizado, por meio da definição na equipe de sucesso, o progresso é documentado. Os próximos passos são planejados, outras pessoas são envolvidas, uma comunidade pode ser construída.

Na próxima seção serão apresentados cases em que o design thinking está sendo aplicado com enfoque no desenvolvimento da educação. 


\section{CASES APLICADOS}

Design thinking é um modelo de pensamento. Significa ter a possibilidade de acreditar que se pode fazer a diferença, desenvolvendo um processo intencional para se chegar ao novo, com soluções criativas e criar impacto positivo.

Faz com que a criatividade inerente ao ser humano se potencialize, pois transforma desafios em oportunidades. Design thinking é a confiança de que novas coisas são possíveis e qualquer pessoa pode fazer acontecer. E de que, na educação, otimismo é bem-vindo. (EDUCADIGITAL, 2013).

Com base nessas premissas, apresentam-se cases de sucesso implantados em várias partes do mundo, inclusive no Brasil, onde a forma de pensar com o design thinking vem construindo possibilidades de se fazer a diferença na Educação, impactando sociedades e as futuras gerações.

\subsection{Ormondale Elementary}

Um exemplo de iniciativa em ambientes de aplicação do design thinking é o caso da escola Ormondale Elementary, da Califórnia.

Para criar uma experiência de aprendizagem conectada às novas tecnologias, a escola aplicou o método durante um ano com alunos e professores. Eles investiram no conceito de aprendizagem investigativa.
Os alunos são vistos não como receptores de informação, mas como formuladores de conhecimento. Para colocar isso na prática, a escola desenvolveu ferramentas digitais de auxílio aos professores e estudantes, formas inovadoras de comunicação com os pais dos alunos e até mesmo uma renovação física da sala de aula, criando um ambiente mais amigável e aberto à colaboração e troca de ideias.

\subsection{Lil' green box}

O lil'green box (CASSIM, 2013) é um projeto realizado pela estudante Micaela Reeves da Universidade de Pretoria para um concurso, o Design Achievers. Esse concurso é uma iniciativa da $\mathrm{SABS}^{2}$ Design Institute para encorajar os estudantes de design da África do Sul a propor ações de impacto social, ambiental ou de problemas industriais vivenciados.

O projeto da estudante partiu de danos ambientais que a sociedade sul-africana produz pelo descarte incorreto de pilhas domésticas. A pesquisa, durante a fase de identificação do problema, indicou que a sociedade sul-africana não tinha uma consciência de questões ambientais. Como resposta a isso, a aluna propôs um sistema de descarte de baterias domésticas criado para o descarte seguro e correto de baterias perigosas.

A iniciativa consiste essencialmente em duas partes, sendo que a primeira parte é destinada a crianças em idades escolar e a segunda parte destinada ao público geral.

\footnotetext{
${ }^{2}$ SABS: South Africa Bureau of Standards. Disponível em: <https://www.sabs.co.za/index.asp>.
} 
A lil' green box é predominantemente voltada para crianças do Ensino Fundamental com idades entre sete e 11 anos.A intenção de Reeves para o projeto era para ser um sistema educacional divertido, mas que incentiva as crianças e, por sua vez, as suas famílias a recolherem e eliminarem suas baterias corretamente e com segurança.

Figura 6: Lil' green box

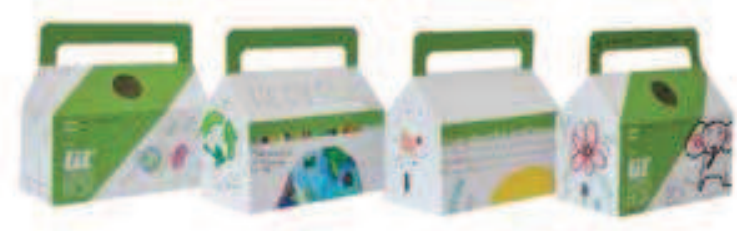

Fonte: Cassim (2013)

O projeto distribui as caixas verdes planas nas escolas primárias, tornando-as acessíveis a professores e crianças. As caixas do bloco são uma ferramenta para os professores educarem as crianças sobre o impacto ambiental negativo e os perigos de baterias, sendo toda a informação ambiental proporcionada no lado interior das caixas.

\section{UMA VEZ QUE O PROFESSOR PAS-} SOU TODAS AS INFORMAÇÕES, AS CRIANÇAS SÃO INCENTIVADAS A VIRAR A CAIXA E INTERAGIR COM

\section{A MESMA, PERSONALIZANDO-}

\section{-A ATRAVÉS DO DESENHO E DA}

\section{ESCRITA.}

Além das atividades de classe, propõe-se que os alunos desenvolvam tarefas em casa, o que exige que as crianças montem as caixas e as levem para casa, oportunizando o incentivo do comportamento sustentável por parte de seus pais. Ao fim de cada semana, as turmas devem trazer suas pilhas usadas para a escola, sendo fornecido um gráfico de descarte de baterias.

Cooperação, construção do projeto junto com os alunos, desenvolvimento de uma nova consciência, diversão. Essas são características do design thinking presentes neste projeto.

\subsection{Edukatu ${ }^{3}$}

O Instituto $\mathrm{Akatu}^{4}$,de São Paulo, queria redesenhar seu antigo site sobre o consumo consciente voltado para crianças e adolescentes para despertar ainda mais o interesse deles pelo tema e incentivar opções práticas de intervenção em suas comunidades. Mas era preciso considerar o contexto digital e as possibilidades de interatividade cada vez mais ampliadas pelos jogos (gamificação) e outros recursos midiáticos.

O Instituto Educadigital ${ }^{5}$ foi parceiro do Akatu para apoiar esse trabalho por meio da abordagem do Design thinking que permitiu planejaro projeto de forma colaborativa com professores da rede pública, designers, jornalistas, além da própria equipe gestora Akatu. Desse processo nasceu o Edukatu, uma rede de aprendizagem aberta e gratuita para professores e alunos do Ensino Fundamental de escolas em todo o Brasil.

O Edukatu convida os participantes a realizarem atividades por meio de circuitos gamificados, que lançam desafios, promovem debate e possibilitam o compartilhamento de produções e atividades das escolas sobre do consumo consciente.

\footnotetext{
${ }^{3}$ Disponível em: <http://edukatu.org.br/>.

${ }^{4}$ Disponível em: <http://www.akatu.org.br/>.

${ }^{5}$ Disponível em: <http://educadigital.org.br/site/>.
} 


\subsection{Design for Change ${ }^{6}$}

Design for Change, de acordo com o website do projeto, é o maior movimento global designado a dar uma oportunidade às crianças de expressarem suas próprias ideias para um mundo melhor e colocá-las em prática. Em 2013, o projeto alcançou 34 países e mais de 300 mil escolas inspirando centenas de milhares de crianças, seus professores e pais, para celebrar o fato de que mudança é possível, e que é possível elas conduzirem esta mudança.

No Brasil, o Design for Change Brasil ${ }^{7}$ foi lançado no ano de 2012. Convidadas a expressar suas inquietações, a imaginar como resolvê-las e a colocar em prática, as crianças são guiadas por quatro verbos: sentir,imaginar, fazer e compartilhar. São elaboradas iniciativas em sala de aula, com crianças de sete a 14 anos, que usam o método para definir seus problemas e encontrar soluções para eles. Percorrendo os verbos do Design For Change, as crianças vivem, de fato, os significados de empatia, colaboração, inovação, pensamento crítico e empoderamento.

\subsection{Escola FazINOVA}

Idealizada pela jovem empreendedora Bel Pesce $^{8}$, a Escola FazINOVA possui três palavras que norteiam todas as suas atividades, que são: descobrir, desenvolver e conectar. $\mathrm{Na}$ FazINOVA, acredita-se que existem dois tipos de pessoas: pessoas talentosas que sabem qual é o seu talento e pessoas talentosas que ainda não descobriram o seu talento. E a melhor maneira de descobrir o seu talento é aprendendo. Por isso, procura professores e abre suas portas para cursos de diversos assuntos: de artes a finanças, de mecatrônica à filosofia, de empreendedorismo à comunicação. É criado um espaço para troca de conhecimento, em que se aprende fazendo.

Os cursos possuem o modelo presencial e online, e neste último os cursos são gratuitos. Caracterizam-se por serem práticos,e os alunos sempre saem com um protótipo.

Os primeiros cursos do programa FazINOVA tratam de três pontos essenciais:

- como se relacionar com pessoas no dia a dia e o impacto disso no que as pessoas fazem;

- como superar desafios com apoio em técnicas de inovação;

- como criar produtos, validá-los e colocá-los no mercado.

\subsection{Khan Academy9}

Formado em Matemática, Ciências da Computação e Engenharia Elétrica pelo MIT, Salman Khan fundou e sustenta uma ONG educacional com a missão de fornecer educação de alta qualidade para qualquer um, em qualquer lugar. Oferece uma coleção grátis de mais de 3.800 vídeos de Matemática, História, Medicina e Saúde, Finanças, Física, Química, Biologia, Astronomia, Economia, Ciência da Computação, entre outras matérias. A Khan Academy já deu mais de 200 milhões de vídeo-aulas gratuitas.

A ideia surgiu quando Khan percebeu que os vídeos eram muito mais interessantes que as

\footnotetext{
${ }^{6}$ Disponível em: <http://www.dfcworld.com/about.html $>$.

${ }^{7}$ Disponível em: <http://www.dfcbrasil.com.br/o-que-e/>.

${ }^{8}$ Disponível em: <http://fazinova.com.br/institucional/a-fazinova/conheca-a-bel/>.

${ }^{9}$ Disponível em: $<$ https://pt.khanacademy.org/about $>$.
} 
aulas que seus primos tinham na escola, pois nos vídeos eles podiam pausar, voltar ao início ou assistirem quantas vezes quisessem, onde bem entendessem. E em pouco tempo os vídeos, inicialmente destinados aos seus primos, começaram a ter mais acessos, e se mostraram eficazes pra qualquer tipo de aprendizado.
Com a missão de mudar a educação para melhor, o que a Khan Academy ${ }^{10}$ tem feito mesmo é inverter a sala de aula, ou o que em inglês é chamado de flip the classroom. Isso mesmo: ele tem colocado a classe de cabeça para baixo, transformando o mundo em uma sala de aula global.

Figura 7: Salomon Khan

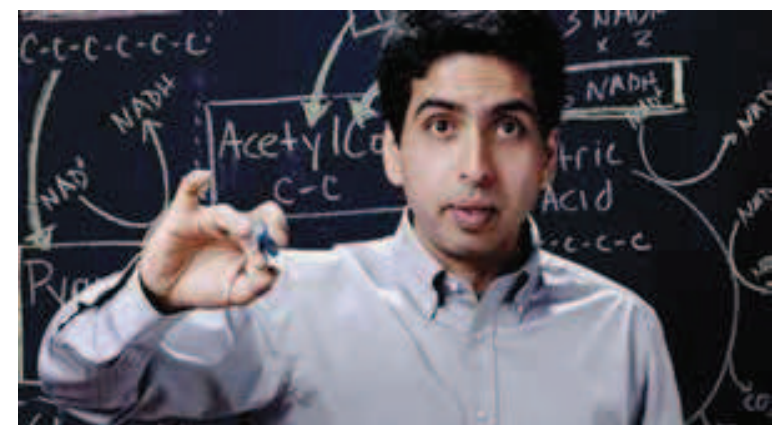

Fonte: Khan Academy

\section{CONCLUSÃO}

A compreensão da importância do design thinking na Educação veio com o entendimento de que, em um ambiente escolar, todos os elementos precisam estar conectados. Esse processo é útil principalmente para que todos os elementos da sociedade que estejam envolvidos no processo educacional aprendam a situar as pessoas, coisas e os porquês no mundo. A comunidade em todas as faixas etárias e níveis educacionais, incluindo a família e a escola, aprendem, na ação colaborativa, a entender suas próprias necessidades e a resolvê-las.
A conexão existente entre os casos apresentados se deu com o enfoque na transformação da sociedade através da transformação do indivíduo, do compartilhamento do conhecimento, da colaboração na construção do conhecimento. Em todos os casos apresentados, percebeu-se a vontade de mudar o mundo, porém cada um fazendo sua parte e sendo parte integrante de um processo em que cada um pode fazer a diferença.

E é este modo de pensar, de se ver a vida, de se viver que define o design thinking. É a possibilidade de construir e realizar através de processos intencionais que impactem positivamente a escola, a sociedade, enfim, o mundo.

\footnotetext{
${ }^{10}$ Disponível em: <https://pt.khanacademy.org/about/the-team>.
} 


\section{THE CONTRIBUTION OF DESIGN THINKING IN EDUCATION}

PERSPECTIVES AND POSSIBILITIES

\section{ABSTRACT}

This article, based upon literature research, aims at presenting design thinking as an approach directed to the creation of innovation and how this approach has been developed in education. The article introduces the concept of design thinking, its characteristics and implements according to the viewpoint of the leading authors and operators in the area. Characteristics such as empathy, collaboration and experimentation, that form the tripod of design thinking, arepresented, as well as various projects, from around the world, focused on education, using this approach as a guiding principle of its activities, emphasizing the interdisciplinary character and showing that through design thinking, the community as a whole learns, in collaborative action, to understand theirown needs and to solve them.

Key-words: Design thinking.

Education. Interdisciplinary.

\section{$* * *$}

\section{REFERÊNCIAS}

ALT, L. Empatia, Colaboração e Experimentação. 2011. Disponível em: <http://luisalt.wordpress. com/2011/09/08/empatia-colaboracao-eexperimentacao/>. Acesso em: 24 jun. 2014.

BARON, J. B.; STEINBERG, R. J. Teaching Thinking skills: Theories and Practice. New York: Freeman, 1987.

BENDIXEN, L. D.; FEUTCHT, F. C. Personal epistemology in the classroom: Theory, research and implications for practice. UK, Cambridge: Cambridge University Press, 2010.

BEREITER, C. Education and mind in the knowledge age. Mahwah, NJ: Lawrence Erlbaum, 2002.

BEREITER, C.; SCARDMALIA, M. Can children really create knowledge? - Canadian Journal of Learning and Technology, 2010, v. 36(1). Disponível em: <http://www.cjlt.ca/index. $\mathrm{php} / \mathrm{cjlt} /$ article/download/585/289>. Acesso em: 26 jun. 2014.

BROWN, T.; WYATT, J. Design thinking for Social Innovation. Stanford Social Innovation Review. California: Leland Stanford Jr. University, 2010.

BROWN, T. Design thinking: uma metodologia ponderosa para decretar o fim das velhas ideias. Rio de Janeiro: Elsevier, 2010.

CASSIM, F. Hands On, Hearts On, Minds On: Design thinking within an Education Context. International Journal of Art \& Design Education (iJADE), Special Issue: Design Education:

International Perspectives and Debates, 2013. v. 32, p. 190-202.

CHAI, C. S. et al. Towards a new era of knowledge creation: A brief discussion of the epistemology for knowledge creation. International Journal of Continuing Engineering Education and Life-long Learning, 2011, v. 21(1), p. 1-12.

DUFOUR, P. Supplying demand for Canada's knowledge society: A warmer future for a cold climate. American Behavioral Scientist, 2010. v. 53(7), p. 983-996. 
EDUCADIGITAL, Instituto. Design thinking para Educadores. Versão em Português: Instituto Educadigital, 2013. Disponível em: <http://issuu. com/dtparaeducadores >. Acesso em: 25 jun. 2014.

ELER, D. Design: O verbo. 2010. Disponível em: $<$ http://www.eler.com.br/index.php/pilares-dodesign-thinking-parte-1-empatia/>. Acesso em: 25 jun. 2014.

GIBSON, J. G. The Theory of Affordances, Perceiving, Acting, and Knowing: Toward an Ecological Psychology, Eds. R. Shaw \& J. Bransford, Hillsdale, NJ: Lawrence Erlbaum, 1977.

GIL, Antonio Carlos. Como elaborar projetos de pesquisa. 4. ed. São Paulo: Atlas, 2002.

HOFER, B. K. Personal epistemology in Asia: Burgeoning research and future directions. The Asia-Pacific Education Researcher, 2010. v. 19(1), p. 179-184.

JONES, Christopher. Métodos de diseño. Barcelona: Gustavo Gilli, 1978.

LEAVY, Brian. Design thinking: a new mental model of value innovation. Emerald Group Publishing Limited. v. 38, n.3, 2010, p. 5-14.

LOCKWOOD, T. Design thinking: Integrating innovation, customer experience, and brand value. New York: Allworth Press, 2009.

MACDONALD, G.; HURSH, D. Twenty-first century schools: Knowledge, networks and new economies. Rotterdam, The Netherlands: Sense Publication, 2006.

MARTIN, Roger. Design thinking: achieving insights via the "knowledge funnel". Emerald Group Publishing Limited. v. 38, n. 2, 2010a, p. 37-41.

The Design of Business: Why Design thinking is the Next Competitive Advantage. Harvard Business School Publishing. Rotman Designworks. 2010b. Disponível em: <http://www. rotmandesignworks.ca/business_design.html >. Acesso em: 23 maio 2014.

NOWESKI, C. et al. Towards a Paradigm Shift in Education Practice: Developing Twenty-First Century Skills with Design thinking, 2012.

OSTERWALDER, A. Business Model Generation - Inovação em Modelo de Negócios: um manual para visionários, inovadores e revolucionários. Rio de Janeiro-RJ: Alta Books, 2013.
PAAVOLA, S.; HAKKARAINEN, K. The knowledge creation metaphor- An emergent epistemological approach to learning. Science \& Education, 2005.v. 14, p. 535-557.

PEIRCE, Charles Sanders. Semiótica e filosofia. São Paulo, Cultrix, Editora Universidade de São Paulo, 1975.

SCHEER, A.; NOWESKI, C.; MEINEL, C. Transforming Constructivist Learning into Action: Design thinking in education, 2009.

SERRAT, Olivier. Design thinking. Knowledge Solutions. March, 2010. p. 78.

TORO, M. E. B. La formacion de la competencia investigativa en los estudiantes del Instituto Tecnologico Metropolitano [archivo de computador]. 2002.

TSAI, C. et al. Positioning Design Epistemology and its Applications in Education Technology. Educational Technology \& Society, 2013. v. 16 (2), p. $81-90$.

VALIMMA, J.; HOFFMAN, D. Knolwegde society discourse and higher education. Higher Education, 2008. v. 56, p. 265-285.

VIANNA, Maurício et al. Design thinking: inovação em negócios. Rio de Janeiro: MJV Press, 2012. 162p.

Data de recebimento: 14/07/14

Data de aprovação: 17/12/14 


\section{SOBRE A AUTORA}

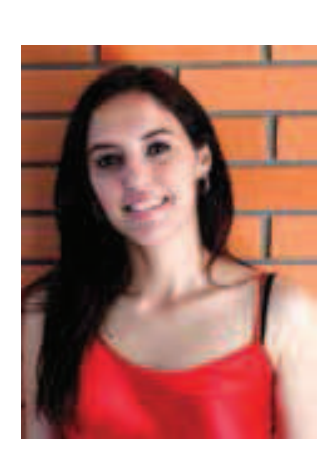

\section{Aline Cristina Antoneli de Oliveira}

Aline Cristina Antoneli de Oliveira possui especialização em TecnologiadaInformação e Comércio Eletrônico pela Universidade Salgado de Oliveira (2005) e graduação em Tecnologia em Processamento pelaUniversidade Estadual de Goiás (2003). Atuou na Universidade Estadual de Goiás nos cursos de Sistemas de Informação, Licenciatura em Informática e Gestão Pública de 2005 a 2010. Atualmente, é professora titular da Faculdade de Tecnologia SENAI/SC em Florianópolis. 